\title{
Further Test on Stock Liquidity Risk with a Relative Measure
}

\author{
Md Hamid Uddin ${ }^{1}$ and Won Kie Ann ${ }^{2}$
}

\begin{abstract}
:
Negative relationship between stock's return and its liquidity suggests that illiquid stocks are riskier than liquid stocks hence illiquid stocks should earn more return. Researchers subsequently considered liquidity as another variable for asset pricing when they found commonality in liquidity. Earlier studies tested stock and market liquidities independently.
\end{abstract}

We therefore further test the relationship of stock's return with its liquidity relative to market-wide liquidity by a relative measure linking the individual liquidity with market-wide liquidity.

Results confirm the negative relationship between stock's return and liquidity, but the relationship is non-linear and the relative measure of liquidity complements the liquidity measures used in prior studies.

We find that fluctuations in relative liquidity do not have positive effect on stock return, raising a question whether variability in liquidity captures liquidity risk.

Key Words: Stock, Liquidity, Relative Liquidity, Risk, and Return

\footnotetext{
${ }^{1}$ Associate Professor of Finance, College of Business Administration, University of Sharjah UnitedArab Emirates, mduddin@sharjah.ac.ae,iba_hu@yahoo.com

Corresponding author: We are benefited from presentation of this paper at National University of Singapore and Prince Sultan University, Riyad, Saudi Arabia. We acknowledge the data management and processing task done by Ms. Soh Siew Eng under our constant guidance.

${ }^{2}$ Professor of Finance, Department of Business Administration, Chang Gung University, Taiwan.
} 


\section{Introduction}

In the capital asset pricing model (CAPM), factors are priced only if they present a form of systematic or non-diversifiable risk. Initially, a stock's co-movement with the market (market beta) was seen as the only form of systematic risk. However, the failure of market beta to explain the cross-sectional expected returns cast doubt on it being the sole important determinant of stock returns (Fama and French 1992 and 1993). As a result, a host of other factors such as firm size and book-to-market ratio have been confirmed in addition to beta in explaining how stock returns are generated.

In contemporary literatures, stock liquidity, which is defined as the ease and speed at which one can trade stocks in the market, is another factor that has been investigated for the purpose. Amihud and Mendelson (1986), Brennan et al. (1996 and 1998), Chordia et al. (1998), Thalassinos et al. (2014a, 2014b) and Fiori (2000) have established a negative relationship between stock's return and the level of its liquidity. This is often interpreted as reflection of liquidity risk premium.

Moreover, Chordia et al. (2000) pointed out that well-known financial events such as the international stock market crash of October 1987 and the liquidity crisis in the bond market in 1998 were not linked to any specific major news, but were characterized by a temporary reduction in aggregate market liquidity. Such liquidity shocks are potential channels through which financial asset prices are influenced by liquidity. It shows that liquidity has a systematic component even after accounting for individual stock's liquidity determinants such as trading volume and its volatility.

Most recently, market wide commonalities also found in Thailand (PukthuanthongLe and Visaltanachoti, 2008). Huberman and Halka (2001) argue that if the systematic component of liquidity cannot be diversified away, a stock should earn a certain amount of compensation return, depending on stock's exposure to the systematic component of liquidity. Pastor and Stambaugh (2003) and Amihud (2002) formally test this proposition. They found that expected stock returns and the level of market liquidity have a negative relationship.

Chordia et al. (2000 and 2001) further expanded the scope of study by showing the importance of the second moment of individual stock liquidity, as measured by trading volume and turnover rate. They hypothesized that variability in individual stock's liquidity should have a positive effect on stock returns as it represents a form of uncertainty to the investors.

However, a negative but surprisingly strong cross-sectional relation was found instead, even after controlling for the size, book-to-market ratio, and momentum effects. They were unable to provide a useful explanation for this unexpected finding. Lately, Goyenko (2005) documents that stock liquidity has a cross-market 
effect, hence the expected stock return includes a premium for liquidity risk, which appears to be a global phenomenon in another study by Liang and Wei, (2006).

We find that, the earlier studies have examined the individual stock liquidity and market liquidity independently, and liquidity measures are based solely on the stock's own characteristics.

However, the key aspect of financial asset pricing models [CAPM or Fama and French (1993) model] is that non-diversifiable risk due to any factor has to be systematically linked to the market-wide effect. Therefore, prior to considering the 'stock liquidity risk' as yet another factor to include in any asset pricing model, we have to further test the relationship of a stock's return with its liquidity relative to the market-wide liquidity. We therefore construct a new relative measure of liquidity (named it relative market liquidity, RML) that links the individual stock liquidity with the average market liquidity, which could be more representative of the liquidity risk. This test is necessary because an infrequently traded stock may not necessarily be considered as illiquid in any particular period if the average market liquidity as a whole is also low during the same period.

In this study, the effect of both the level and variability of this proposed liquidity measures on stock excess return ${ }^{3}$ are tested using US data over a long period of 360 months from 1966 to 1995 . The result confirms a negative relationship between the excess stock return and level of relative market liquidity, as documented by prior studies, but detects that the negative relationship is non-linear - suggesting a more than proportional increase in liquidity risk as a stock become more and more illiquid. The relative measure of liquidity is also found to be complementing the liquidity measures used by earlier studies.

Another finding is that variability of relative market liquidity does not have significant positive relationship with the excess stock return, indicating that investors may not necessarily concern much about the fluctuations of a stock's liquidity, provided that its liquidity is higher relative to the average market liquidity. The variability of liquidity may therefore not capture the liquidity risk, raising a new research question whether fluctuation of liquidity is indicative of stock illiquidity. In a nutshell, by using a relative measure of liquidity, this study confirms the existence of liquidity risk that can be considered for including in financial asset pricing model while shedding new light on the nature and significance of liquidity risk.

The rest of paper is organized as follows: hypotheses are discussed in the next section. Section 3 introduces the data and methodology used. The findings and analysis are presented in Section 4. Section 5 gives a concluding remark.

\footnotetext{
${ }^{3}$ The excess return is calculated as monthly stock return minus one-month T-bill rate. The excess return of a stock above the risk-free rate ( $T$-bill rate) is considered to be the premium for non-diversifiable risks that investors must bear.
} 


\section{Hypotheses}

A new relative market liquidity measure is computed for each stock in each month as the ratio of a stock's turnover volume (in terms of number of shares) to the average market turnover volume (excluding that of the stock itself). We believe that the liquidity of other stocks in the market has a role to play in measuring the liquidity of the stock in question. For instance, the turnover volume of stock $j$ in month $t$ may be low (indicating less liquid) but if the average market turnover volume for the month is also low, then relatively, stock $j$ should not be perceived as that much illiquid. Intuitively, a stock's liquidity scaled by the other stocks' average liquidity should provide a better assessment of its liquidity than that solely based on its own specific characteristics.

Earlier researchers documented a negative relationship between the stock return and level of its liquidity [e.g., Amihud and Mendelson (1986), Brennan et al. (1996 and 1998), Chordia et al. (2001) and Fiori (2000)]. This suggests that infrequently traded stocks provide higher returns to investors. This has been interpreted as the reflection of liquidity risk premium, since illiquid stocks which are infrequently traded might be riskier than frequently traded stocks as investors cannot quickly adjust their portfolio of investments when it becomes necessary. Therefore, investors should require a premium for bearing non-diversifiable liquidity risk and if the relative measure of liquidity, as described above, captures a significant part of the liquidity risk then we can hypothesize as follows:

The relationship between the level of relative market liquidity and excess stock returns is negative (Hypothesis I).

Apart from illiquidity of stocks, the variability in the level of liquidity is also considered to be risky to the investors as the more the stock liquidity fluctuates, the higher the uncertainty in market trading. This leads to erosion of investors' confidence in the trading activates. This is because investors realize that their assessment of the likelihood of things going wrong has become less reliable. Therefore, investors would expect high return for trading in a market with more volatile trading behavior, and hence we can hypothesize as follows:

The relationship between the variability of relative market liquidity and excess stock returns is positive (Hypothesis II).

These two hypotheses are tested in this paper using the cross-sectional regressions over a long period of time. If both the hypotheses appear to be true in empirical examination then we can comfortably accept that the liquidity risk does indeed systematically matter the investors in market. Therefore, a premium can be expected for non-diversifiable liquidity risk as argued by the other researchers mentioned earlier. 


\section{Data and Methods}

Monthly required data for the period from January 1966 to December 1995 were collected from CRSP and COMPUSTAT databases for all the common stocks listed on the New York Stock Exchange (NYSE) and American Stock Exchange (AMEX). ${ }^{4}$ A stock is included in a given month's sample set if (1) its return and trading volume data in the current month, $t$, and in at least 36 of the past 60 months (relative to the current month $t$ ) are available from CRSP; (2) sufficient data is available to calculate the firm size and price as of month $t-2$, and turnover in the past 36 months; (3) adequate data is available on COMPUSTAT database to calculate the book to market ratio as of December of the previous year (relative to current year).

Having colleted the required data for all months, we have computed two measures of liquidity: (i) turnover rate and (ii) relative market liquidity, as discussed earlier. The relative market liquidity is the new measure of stock liquidity proposed in this study while the turnover rate is used by the other studies examining the stock liquidity. Using of both the measures of liquidity in this paper would help us comparing the results from this study with those of the other studies.

For every month, the following variables were calculated for each stock in order to determine the characteristics of the stocks included in the sample set:

1. SIZE - Market value of firm's equity as of the end of the second month to the last month.

2. BM - The ratio of the book value of equity to the market value of equity, using the end of the previous year market and book values. As in Fama and French (1992), the value of BM for July of the year $t$ to June of the year $t+l$ was computed using accounting data at the end of the year $t-1$. To reduce the effect of outliers, book-to-market ratio values greater than the 0.995 fractal or less than the 0.005 fractal were set equal to the 0.995 and 0.005 fractal values respectively.

3. TURN - The stock turnover rate is measured by the number of stocks traded divided by the number of stocks outstanding in the second to the last month.

4. STDTURN - The standard deviation of turnover calculated over the past 36 months beginning in the second to the last month.

5. CVTURN - The coefficient of variation of turnover calculated over the past 36 months beginning in the second to the last month. Coefficient of variation is calculated as STDTURN divided by the mean over the past 36 months.

6. PRICE - The reciprocal of the stock price reported at the end of the second to last month.

\footnotetext{
4 Data is restricted to NYSE and AMEX-listed stocks because NASDAQ returns and volume data are not available from CRSP prior to November 1982. Furthermore, reported volumes on NASDAQ include inter-dealer trades, unlike the volumes reported on the NYSE and the AMEX.
} 
After the above computations, stocks are selected for a given month's sample set if none of the above variables is missing. The relative market liquidity measure, RML, is then calculated for each stock in each month using the formula below.

$\mathrm{RML}_{\mathrm{j}, \mathrm{t}}=\mathrm{TV}_{\mathrm{j}, \mathrm{t}} / \mathrm{ATV}_{\mathrm{N}-\mathrm{j}, \mathrm{t}}$

Where, $\mathrm{TV}_{\mathrm{j}, \mathrm{t}}$ is the turnover volume (in terms of number of shares) of stock $j$ in the sample in month $t(\mathrm{t}=1$ to 360$)$ and $\mathrm{ATV}_{\mathrm{N}-\mathrm{j}, \mathrm{t}}$ is the average turnover volume of all other stocks except stock $j$ itself. Variability of RML is then calculated in a similar fashion as the variability in the individual liquidity (STDTURN and CVTURN):

i. $\quad S_{T D R M L}, \mathrm{t}$ - The standard deviation of RML calculated over the past 36 months beginning in the second to the last month.

ii. $\quad$ CVRML $_{\mathrm{j}, \mathrm{t}^{-}}$the coefficient of variation of RML calculated over the past 36 months beginning in the second to the last month. Coefficient of variation is calculated as STDRML divided by its mean over the past 36 months.

Regression tests are then conducted for each month (Jan 1966 to Dec 1995) across the selected stocks. The excess return ${ }^{5}$ of stock $j$ in month $t$ is regressed on the explanatory variables (i.e. two measures of stock liquidity and other stock characteristics such as firm size and book-to market ratio) at month $t$-2, so that the regressors explain stock returns in the future. After that, the 360 monthly cross sectional slope coefficients of explanatory variables are averaged and tested for significance. The t-statistic is obtained by dividing the average slope coefficients by the standard error of their 360 time-series slope coefficients. The average sample size is 1,254 stocks in each month. The general form of regression equation for stock $j$ in month $t$ is as follows:

Excess Stock Returns $_{j, t}=\alpha_{0}+\sum \alpha_{c}$ stock $_{\text {characteristics }}^{j, t-2}+\alpha_{L}$ Liquidity $_{j, t-2}$

$$
+\alpha_{v} \text { Variability of liquidity }{ }_{j, t-2}+\varepsilon_{j, t}
$$

\section{Findings and Discussions}

Table 1 presents the time-series averages of the monthly cross-sectional descriptive statistics of the explanatory variables. As they exhibit substantial skewness, their natural logarithm values are used in the regression analysis. This transformation is to reduce skewness that has been employed by the past studies [Chordia et al. (2001) and Lo and Wang (2000)]. Table 2 presents the averages of the monthly crosssectional correlations of some of the logged variables. The highest correlated variables are RML and STDRML, CVRML and CVTURN, SIZE and RML, SIZE and PRICE, and TURN and STDTURN. From the correlation matrix in Table 2, we can understand that multicollinearity should not be a major problem as all the other pair-wise correlations are not very high in absolute values. SIZE and PRICE are highly correlated but PRICE will be omitted as TURN has been used and shown to

\footnotetext{
${ }^{5}$ See footnote 1 for calculation of excess stock return.
} 
be significant in many studies. Moreover, PRICE is insignificant in all the tests in Chordia et al. (2001). The coefficient of variation of both RML and TURN are used instead of their respective standard deviations as the two variables are highly correlated with their standard deviations.

Table 1: Descriptive Statistics of Explanatory Variables

\begin{tabular}{|l|l|l|l|l|l|l|l|l|}
\hline & RML & STDRML & CVRML & $\begin{array}{c}\text { SIZE } \\
(\$ \text { billion })\end{array}$ & TURN & STDTURN & CVTURN & BM \\
\hline $\begin{array}{l}\text { Mean } \\
\text { Standard } \\
\text { Error }\end{array}$ & 1.0316 & 0.4805 & 0.5884 & 1.0623 & 0.0377 & 0.0235 & 0.6164 & 1.0114 \\
\hline Median & 0.3456 & 0.0228 & 0.0079 & 0.1078 & 0.0014 & 0.0017 & 0.0082 & 0.0338 \\
\hline $\begin{array}{l}\text { Standard } \\
\text { Deviation }\end{array}$ & 1.8955 & 0.7814 & 0.2748 & 3.8118 & 0.0491 & 0.0577 & 0.2844 & 1.2042 \\
\hline $\begin{array}{l}\text { Sample } \\
\text { Variance }\end{array}$ & 3.6517 & 0.6250 & 0.0763 & 29.5836 & 0.0063 & 0.0095 & 0.0819 & 1.8438 \\
\hline $\begin{array}{l}\text { Kurtosis } \\
\text { Skewness }\end{array}$ & 38.78383 & 56.1477 & 15.2038 & 218.0781 & 77.1242 & 217.0906 & 14.9851 & 291.3290 \\
\hline Range & 22.8023 & 10.0986 & 2.9878 & 80.5336 & 0.8001 & 1.5393 & 3.0299 & 29.0516 \\
\hline Minimum & 0.0027 & 0.0047 & 0.1601 & 0.0014 & 0.0002 & 0.0004 & 0.1905 & 0.0151 \\
\hline Maximum & 22.8050 & 10.1034 & 3.1478 & 80.5350 & 0.8004 & 1.5397 & 3.2203 & 29.0668 \\
\hline
\end{tabular}

The descriptive statistics represent the time series averages of the monthly crosssectional statistics of explanatory variables from January 1966 to December 1995. To be included in a given month t, a stock has to fulfill these criteria: (1) Its returns in the current month $\mathrm{t}$, and in at least 36 of the past 60 months are available from CRSP; (2) Sufficient information are available to compute the firm size (SIZE) as of month $\mathrm{t}-2$, and turnover over the previous 36 months; (3) Adequate data are available from COMPUSTAT to compute the book-to-market ratio using accounting data of the previous year. RML is the natural logarithm of the ratio of the stock turnover to the average market stock turnover, and CVRML is the natural logarithm of the coefficient of variation of RML computed using data over the past 36 months, starting from month t-2. SIZE represents the natural logarithm of the market value of equity (i.e. price $x$ shares outstanding) in billions of dollars. TURN represents the natural logarithm of the stock turnover, and CVTURN is the natural logarithm of the coefficient of variation of TURN computed using data over the past 36 months, starting from month $\mathrm{t}-2$. BM is the natural logarithm of the ratio of book value of equity plus deferred taxes to market value of equity. Book-to-market ratio (BM) provides summary statistics for this variable after book-to-market ratios greater than the 0.995 fractal or less than the 0.005 fractal are set equal to 0.995 and 0.005 fractal values, respectively. The standard deviation (STD) and coefficient of variation (CV) of stock turnover (TURN) and the relative market liquidity (RML) are computed 
using data over the past 36 months, starting from month t-2. The average monthly sample size is 1,254 stocks.

Table 2: Correlation Matrix of Variables

\begin{tabular}{|l|l|l|l|l|l|l|l|l|l|l|}
\hline & $\begin{array}{l}\text { Excess } \\
\text { Returns }\end{array}$ & RML & $\begin{array}{l}\text { STDRM } \\
\text { L CVRM }\end{array}$ & SIZE & PRICE & TURN & $\begin{array}{l}\text { STDT } \\
\text { URN }\end{array}$ & $\begin{array}{l}\text { CVTU } \\
\text { RN }\end{array}$ & BM \\
\hline $\begin{array}{l}\text { Excess } \\
\text { Returns }\end{array}$ & 1.0000 & & & & & & & & & \\
\hline RML & -0.0181 & 1.0000 & & & & & & & & \\
\hline $\begin{array}{l}\text { STDRM } \\
\text { L }\end{array}$ & -0.0211 & 0.8786 & 1.0000 & & & & & & & \\
\hline CVRML & 0.0063 & -0.4269 & -0.1636 & 1.0000 & & & & & & \\
\hline SIZE & -0.0179 & 0.7664 & 0.6762 & -0.5400 & 1.0000 & & & & & \\
\hline PRICE & 0.0118 & -0.4005 & -0.2893 & 0.3776 & -0.7620 & 1.0000 & & & & \\
\hline TURN & -0.0095 & 0.6332 & 0.5072 & -0.0794 & 0.1214 & -0.1175 & 1.0000 & & & \\
\hline $\begin{array}{l}\text { STDTUR } \\
\text { N }\end{array}$ & -0.0100 & 0.2205 & 0.4161 & 0.3799 & -0.2199 & 0.1631 & 0.6806 & 1.0000 & & \\
\hline $\begin{array}{l}\text { CVTUR } \\
\text { N }\end{array}$ & 0.0057 & -0.4437 & -0.2357 & 0.8640 & -0.6007 & 0.4374 & -0.0408 & 0.4622 & 1.0000 & \\
\hline BM & 0.0206 & -0.2870 & -0.2554 & 0.1242 & -0.3291 & 0.3326 & -0.1629 & -0.0605 & 0.1713 & 1.0000 \\
\hline
\end{tabular}

The correlation matrix is the time series averages of the monthly cross-sectional correlations of the firm characteristics for the 360 months. Excess returns refer to monthly stock returns - the one-month Treasury bill rate. RML is the natural logarithm of the ratio of stock volume to the market stock volume, and STDRML and CVRML are the natural logarithms of the standard deviation and coefficient of variation of RML computed using data over the past 36 months, starting from month $\mathrm{t}-2$. SIZE represents the natural logarithm of the market value of equity (i.e. price * stocks outstanding) in billions of dollars. PRICE is the natural logarithm of the reciprocal of the stock price at month $\mathrm{t}-2$. TURN represents the natural logarithm of the stock turnover, and STDTURN and CVTURN are natural logarithms of the standard deviation and coefficient of variation of TURN computed using data over the past 36 months, starting from month $\mathrm{t}-2$. BM is the natural logarithm of the ratio of book value of equity plus deferred taxes to market value of equity after book-tomarket ratio values greater than the 0.995 fractal or less than the 0.005 fractal are set equal to the 0.995 and 0.005 fractal values, respectively. Average monthly sample size is 1,254 stocks.

Using RML as liquidity proxy, stock excess returns are regressed on the selected explanatory variables and results are reported in panel A of Table 3. Panel B reports the results when the tests are repeated using TURN as liquidity measure. Book-to market ratio, BM, proves to be the most significant variable in explaining stocks' 
excess returns, with t-statistics of around +3.00 in both sets of tests. On the other hand, SIZE shows insignificance in Panel A with t-statistic of -1.6225 and -1.8172 but highly significant at $1 \%$ confidence level in Panel B. Both these variables have their expected signs. Both RML and TURN are significant at $10 \%$ level and this evidence supports the first hypothesis that the proposed variable, RML, has a negative relationship with excess stock returns. CVTURN is negatively significant at $5 \%$ level, which is consistent with earlier findings by Chordia et al. (2001). However, the negative sign of CVRML (significant at 10\% level) is opposite to the expectation in hypothesis II. Therefore, hypothesis II is not supported.

Table 3. Time series averages of monthly cross-sectional regressions of excess stock returns on both level and variability of illiquidity and other stock characteristics

\begin{tabular}{|c|c|c|c|c|}
\hline \multirow[b]{2}{*}{ Intercept } & \multicolumn{2}{|c|}{ Panel A: RML } & \multicolumn{2}{|c|}{ Panel B: Turnover } \\
\hline & $\begin{array}{l}0.5921 * * \\
(2.520994)\end{array}$ & $\begin{array}{l}0.4831 * * \\
(1.9670)\end{array}$ & $\begin{array}{l}0.6555 \\
(1.4646)\end{array}$ & $\begin{array}{l}0.3656 \\
(0.7879)\end{array}$ \\
\hline SIZE & $\begin{array}{l}-0.1291 \\
(-1.6225)\end{array}$ & $\begin{array}{l}-0.1423 * \\
(-1.8172)\end{array}$ & $\begin{array}{l}-0.1534 * * * \\
(-3.0062)\end{array}$ & $\begin{array}{l}-0.1570 * * * \\
(-3.1689)\end{array}$ \\
\hline $\mathrm{BM}$ & $\begin{array}{l}0.2099 * * * \\
(2.9901)\end{array}$ & $\begin{array}{l}0.2033 * * * \\
(2.9425)\end{array}$ & $\begin{array}{l}0.2228 * * * \\
(3.2740)\end{array}$ & $\begin{array}{l}0.2065 * * * \\
(3.0939)\end{array}$ \\
\hline RML & $\begin{array}{l}-0.1057^{*} \\
(-1.7426) \\
\end{array}$ & $\begin{array}{l}-0.0900 \\
(-1.4964)\end{array}$ & 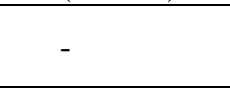 & 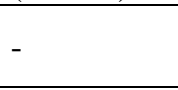 \\
\hline CVRML & - & $\begin{array}{l}-0.1348 * \\
(-1.7961) \\
\end{array}$ & - & - \\
\hline TURN & - & - & $\begin{array}{l}-0.1261 * \\
(-1.9484) \\
\end{array}$ & $\begin{array}{l}-0.1427 * * \\
(-2.2660) \\
\end{array}$ \\
\hline CVTURN & - & - & - & $\begin{array}{l}-0.1908 * * \\
(-2.3339) \\
\end{array}$ \\
\hline
\end{tabular}

*** significant at the $1 \%$ level

** significant at the $5 \%$ level

* significant at the $10 \%$ level

Panel A shows results using relative stock turnover, RML, as the liquidity proxy while Panel B shows results using stock turnover. RML is the natural logarithm of the ratio of the stock turnover to the average market stock turnover, and CVRML is the natural logarithm of the coefficient of variation of RML computed using data over the past 36 months, starting from month t-2. SIZE represents the natural logarithm of the market value of equity (i.e. price $\mathrm{x}$ shares outstanding) in billions of dollars. TURN represents the natural logarithm of the stock turnover, and CVTURN is the natural logarithm of the coefficient of variation of TURN computed using data over the past 36 months, starting from month t-2. BM is the natural logarithm of the ratio of book value of equity plus deferred taxes to market value of equity. The coefficients shown in this table are the time series averages of the 360 monthly cross-sectional regression coefficients and all coefficients are multiplied by 100 . Tstatistics are in parentheses and they are computed using the average slope coefficients divided by their time series standard error. The average monthly sample size is 1,254 stocks. 
It is also possible that TURN and RML will better reflect a stock's liquidity when used together and this will be tested next. As CVTURN and CVRML are highly correlated at 0.864 , we dropped CVTURN, as we are interested to find out the effects of the new measure.

Column 1 of Table 4 shows the result when TURN, RML and CVRML are included in the same test. The significance of RML dropped considerably from a t-statistic of -1.496 (Table 3 Panel A) to -0.663 . On the other hand, CVRML's explanatory power rose from $10 \%$ level (Table 3: t-statistic $=-1.796)$ to $5 \%$ level (t-statistic $=-$ 2.001). BM remains highly significant at $1 \%$ level and SIZE at $10 \%$ level. The significance of TURN has dropped as compared to Panel B of Table 3. However, this does not imply that RML is a substitute for TURN. Rather, it is more appropriate to see them as complementing each other.

We also explore the possibility of a non-linear relationship between the liquidity and stock returns. Column 2 of Table 4 reports the results when the squared terms of SIZE, RML and TURN are included as explanatory variables. To avoid multicollinearity effects, CVTURN is omitted as it is highly correlated to CVRML. $\mathrm{BM}$ remains significant at $1 \%$ level with a t-statistic of 2.9030 . Both $\mathrm{SIZE}^{2}$ and $\mathrm{RML}^{2}$ are highly significant at $1 \%$ level which means there is strong non-linearity between RML and stock excess returns, and between SIZE and stock excess returns.

This result proved that stock returns and RML has a very significant non-linear relationship, which leads to CVRML becoming insignificant. Thus, the significant negative sign of CVRML in Table 3 (t-statistic $=-1.796$ ) could be largely caused by the non-linearity of this relationship. RML seems to capture a new aspect of stock's liquidity, which is better than TURN, as the significance of TURN and TURN ${ }^{2}$ became insignificant after including $\mathrm{RML}$ and $\mathrm{RML}^{2}$. It seems to confirm that hypothesis II is not supported.

In the above tests, stock's systematic risk (BETA) was not included as an explanatory variable. Although Chordia et. al. (2001) used both stock excess returns (i.e. unadjusted for BETA) and risk-adjusted returns (i.e. taken BETA into account) in their tests; they showed that the exclusion of BETA did not affect their findings and conclusions. Fama and French (1992 and 1993) have also showed that BETA becomes insignificant when considered together with other variables such as SIZE and BM ratio. Column 3 of Table 4 shows the results when BETA is included in regression ${ }^{6}$. The results are generally similar and $\mathrm{SIZE}^{2}, \mathrm{BM}$ and $\mathrm{RML}^{2}$ retain their significance at $1 \%$ level with t-statistics $=2.9589,2.9420$ and -3.1532 , respectively. The inclusion of BETA does not affect the findings and BETA itself proved to be insignificant.

\footnotetext{
${ }^{6}$ BETA for each stock is estimated by market model using at least 36 available monthly stock returns of the past 60 months relative to the current month $t$.
} 
Table 4. Time series averages of monthly cross-sectional regressions of stock excess returns on both level and variability of illiquidity, Market Beta, and other stock characteristics, including squared terms of SIZE, TURN, and RML

\begin{tabular}{|l|l|l|l|}
\hline & Column 1 & Column 2 & Column 3 \\
\hline Intercept & 0.0474 & -0.1014 & -0.0805 \\
& $(0.0772)$ & $(-0.1472)$ & $(-0.1249)$ \\
\hline SIZE & $-0.1924 *$ & -0.0421 & -0.0343 \\
& $(-1.6845)$ & $(-0.4160)$ & $(-0.3770)$ \\
\hline \multirow{2}{*}{ IIZE $^{2}$} & - & $0.0302 * * *$ & $0.0305 * * *$ \\
& & $(2.9264)$ & $(2.9589)$ \\
\hline \multirow{2}{*}{ BM } & $0.1734 * * *$ & $0.1766 * * *$ & $0.1676 * * *$ \\
& $(2.8163)$ & $(2.9030)$ & $(2.9420)$ \\
\hline \multirow{2}{*}{ RML } & -0.0744 & -0.0505 & -0.0671 \\
& $(-0.6630)$ & $(-0.4987)$ & $(-0.7050)$ \\
\hline \multirow{2}{*}{ RML ${ }^{2}$} & - & $-0.0283 * * *$ & $-0.0285 * * *$ \\
& & $(-3.1066)$ & $(-3.1532)$ \\
\hline \multirow{2}{*}{ CVRML } & $-0.1440 * *$ & -0.0752 & -0.0691 \\
& $(-2.001)$ & $(-1.0610)$ & $(-1.0183)$ \\
\hline \multirow{2}{*}{ TURN } & $-0.2310 *$ & -0.2739 & -0.2530 \\
& $(1.8901)$ & $(-1.4229)$ & $(-1.3588)$ \\
\hline \multirow{2}{*}{ TURN ${ }^{2}$} & - & -0.0294 & -0.0275 \\
& & $(-1.5744)$ & $(-1.5385)$ \\
\hline \multirow{2}{*}{ BETA } & - & - & 0.0330 \\
& & & $(0.2037)$ \\
\hline
\end{tabular}

*** significant at the $1 \%$ level

** significant at the $5 \%$ level

* significant at the $10 \%$ level

This table presents the results when the squared values of SIZE, RML and TURN (denoted by SIZE2, RML2 and TURN2 respectively), and market beta (BETA) are included as additional regressors. The sample and variables are defined as in Table 2. The coefficients shown in this table are the time series averages of the 360 monthly cross-sectional regression coefficients and all coefficients are multiplied by 100. T-statistics are in parentheses and they are computed using the average slope coefficients divided by their time series standard error.

The average monthly sample size is 1,254 stocks. The overall evidence confirms the hypothesis I that predicts a negative relationship between the excess stock returns and level of relative market liquidity, RML. This suggests that investors do not assess a stock's liquidity based only on its specific characteristics. If a stock's RML falls, investors will require a liquidity premium as compensation for holding relatively less liquid stocks.

This finding generally supports the results of earlier studies, where stock specific liquidity measures such as stock's turnover rate and dollar trading volume were used. Our results also show that the relative market liquidity measure, RML, is 
negatively but non-linearly related to the stock returns. The non-linear relationship between the stock excess return and liquidity detected by our relative measure, RML, is new evidence, which suggests that liquidity risk increases at more than proportional rate as a stock becomes more and more illiquid and its expected risk premium also increases at higher than proportional rate. The hypothesis II is intended to examine whether the liquidity risk can also be captured by the variability of a stock's RML The conventional knowledge is that the fluctuation in stocks' liquidity indicates uncertainty of the investors' cash flow. Therefore, hypothesis II expects to find a positive relationship between the variability of relative market liquidity, CVRML, and the excess stock return. Initially, we found a significant negative relationship between stock return and CVRML.

However, this significance did not persist when the squared term of RML is included in the same test. The results do not support this hypothesis. Indeed, the findings seem to suggest that hypothesis II was not consistent with the real world investors' behavior. The investors may not that much concern about the fluctuations in a stock's liquidity provided that its liquidity is higher relative to the average market liquidity. It is logical to assess a stock's liquidity by comparing it to the market's liquidity as well as looking at liquidity measure based on the stock's own characteristics. Therefore, RML is not a substitute but a complement to the existing liquidity measures.

Another possible implication of the evidence not supporting the hypothesis II is that liquidity risk may not be captured by the variability in liquidity. Fluctuations in stock's liquidity can be a double-edged sword. If liquidity risk arises from investors' relative inability to trade, then a reasonable question is whether the fluctuation in liquidity is indicative of a less liquid market or not. Currently, there is no much prior knowledge ${ }^{7}$ about this aspect of liquidity risk that can suggest any particular pattern of the relationship between the variability of liquidity and stock return. The findings of our study however do provide a general indication that variability in liquidity might not necessarily lead to an illiquid market.

\section{Conclusions}

Researchers documented a negative relationship between the stock's return and the level of its liquidity using data from the US market [e.g., Amihud and Mendelson (1986), Brennan et al. (1998), Chordia et al. (2000 and 2001) and Fiori (2000)]. This

\footnotetext{
${ }^{7}$ The variability in liquidity however might imply heterogeneity in investors' expectation, leading to lower required return (Merton, 1987). If market heterogeneity increases with higher variability in liquidity, investors would lower their required return. Therefore, a negative relationship between the variability in liquidity and stock return may be emerged. This analysis was provided by Chordia et al. (2000 and 2001) in order to explain a significant negative relationship between the variability of turnover rate and excess return of stock.
} 
suggests that infrequently traded stocks provide higher return to the investors, which has been interpreted as reflection of liquidity risk premium.

In further studies, Chordia (2000), Huberman and Halka (2001) and Pastor and Stambaugh (2003) found that the stock liquidity has a market-wide common element. If this common element of liquidity cannot be diversified away then they suggest that stock liquidity should be considered as another factor of asset pricing model. Goyenko (2005) and Liang and Wei (2006) have made a step further by producing new evidence that liquidity premium is indeed a part of expected stock return.

While the research on stock liquidity has progressively been receiving attention of academic researchers, we found a lack in the earlier studies that they have examined the individual stock liquidity and market liquidity independently, and measures are based solely on the stock's own characteristics. If stock liquidity has to be considered as another factor in asset pricing model, we should re-examine the liquidity risk from different perspectives. In this paper, we have further tested the relationship of a stock's excess return with the stock liquidity relative to market-wide liquidity (the new measure of liquidity is named as: relative market liquidity, RML). This further test was necessary because the liquidity of other stocks in the market has a role to play in measuring the liquidity of the stock in question. An infrequently traded stock may not necessarily be considered as illiquid in any particular period if the average market liquidity as whole is also low during the same period.

The evidence produced in this paper confirms our first hypothesis that a negative relationship exists between the excess stock return and level of relative market liquidity. This result supports the findings of earlier studies using other liquidity measures such as stock's turnover rate and dollar trading volume. However, the new finding is that a stock's relative market liquidity is negatively but non-linearly related to its excess stock return, suggesting that the liquidity risk increases at more than proportional rate as a stock becomes more and more illiquid. Results also show that the new relative measure of liquidity is not a substitute to other liquidity measures used by earlier studies but they seem to complement each other.

Lastly, the surprising finding is that evidence does not support our second hypothesis that there exists a positive relationship between the variability of relative market liquidity and the excess stock return. This result lends a distant support to earlier evidence of negative relationship between the excess stock return and variability of liquidity measured by stock's turnover rate (Chordia et al., 2000 and 2001). But our findings could have a meaningful explanation that investors may not necessarily concern highly about the fluctuations of a stock's liquidity, provided that its liquidity is higher relative to the average market liquidity.

Therefore, liquidity risk may not be captured by the variability of stock liquidity. If liquidity risk originally arises from investors' inability to trade, then a reasonable 
question is whether the fluctuation in liquidity is indicative of an illiquid market. Currently, there is a lack of knowledge on this aspect of liquidity risk, but our current findings seem to indicate that variability in liquidity might not necessarily lead to an illiquid market. Future research will however explore more on this issue.

\section{References}

Amihud, Y., Mendelson, H. 1986, “Asset Pricing and the Bid-Ask Spread,” Journal of Financial Economics, Vol. 17, pp. 223-249.

Amihud, Y. 2002, "Illiquidity and Stock Returns: Cross-Section and Time-Series Effects," Journal of Financial Markets, Vol. 5, pp. 31-56.

Brennan, M., Chordia, T., Subrahmanyam, A. 1996, "Cross-Sectional Determinants of Expected Returns," in Lehmann, M. (Ed.), on Finance: In Honor of Fischer Black, Oxford University Press.

Brennan, M., Chordia, T., Subrahmanyam, A. 1998, “Alternative Factor Specifications, Security Characteristics, and the Cross-Section of Expected Stocks Returns," Journal of Financial Economics, Vol. 49, pp. 345-364.

Chordia, T., Roll, R., Subrahamyam A. 2000, “Commonality in Liquidity,” Journal of Financial Economics, Vol. 56, pp. 3-28.

Chordia, T., Roll R., Subrahmanyam A., Anshuman, V. 2001, "Trading Activities and Expected Stock Returns," Journal of Financial Economics, Vol. 59, pp. 2-32.

Fama, E., and French, K. 1992, "The Cross Section of Expected Stock Returns," Journal of Finance, Vol. 47, pp. 427-466.

Fama, E., French, K. 1993, "Common Risk Factors in the Returns on Stocks and Bonds," Journal of Financial Economics, Vol. 33, pp. 3-56.

Fiori, F., 2000, "Liquidity Premia in the Equity Markets: An Investigation into the Characteristics of Liquidity and Trading Activity," Working Paper, University of Chicago.

Goyenko, R., 2005, "Stock and Bond Pricing with Liquidity Risk”, Working Paper, Indiana University.

Liang, S. X. and Wei, K. C. J, 2006, “Global Liquidity Risk”, Working Paper, Hong Kong University of Science and Technology.

Huberman, G., Halka, D. 2001, “Systematic Liquidity,” Journal of Financial Research, Vol. 24, pp. 161-178.

Merton R. 1987, “A Simple Model of Capital Market Equilibrium with Incomplete Information," Journal of Finance, Vol. 42, pp. 483-510.

Pastor, L., and Stambaugh, R. F. 2003, "Liquidity Risk and Expected Stock Returns," Journal of Political Economy, Vol. 111 (3), pp. 642-685.

Pukthuanthong-Le, K. and Visaltanachoti, N. 2008, "Commonality in Liquidity: Evidence from the Stock Exchange of Thailand.”, Pacific-Basin Finance Journal.

Thalassinos, I.E., Liapis, K. and Thalassinos, E.J., 2014a, „The role of the rating companies in the recent financial crisis in the Balkan and black sea area", Chapter book in Economic Crisis in Europe and the Balkans, 79-115, Contributions to Economics, Springer International Publishing, DOI: 10.1007/978-3-319-00494-5-6.

Thalassinos, I.E. and Liapis K., 2014b, „Segmental financial reporting and the internationalization of the banking sector", Chapter book in, Risk Management: Strategies for Economic Development and Challenges in the Financial System,(eds), D. Milos Sprcic, Nova Publishers, 221-255, ISBN: 978-163321539-9; 978$\underline{163321496-5 .}$ 